\title{
Dual Frequencies Usage by Full and Incomplete Ring Elements
}

\author{
Kamarulzaman Mat ${ }^{1}$, Norbahiah Misran ${ }^{2}$, Mohammad Tariqul Islam ${ }^{3}$, Mohd Fais Mansor ${ }^{4}$ \\ Department of Electrical, Electronic and System Engineering \\ Faculty of Engineering and Built Environment, Universiti Kebangsaan Malaysia \\ 43600 Bangi, Selangor, Malaysia
}

\begin{abstract}
Full and incomplete ring patch elements antenna can be mixed to generate a variety of responses with respect to the direction of polarization. Dual frequencies requirement in numerous usage like in tracking radar can be achieved by combining the patches. To obtain the favored operating frequency, a straightforward design of a ring patch and also the addition of a gap have been utilized. Various sizes of the gap and the gap's position within a ring have been examined in the study. In order to investigate the element conduct, the surface current distribution, return loss, as well as reflection phase, are monitored. The evaluation revealed that the ring element with a smaller width would offer a sharp gradient of reflection phase that lowers its bandwidth performance. Meanwhile, the element performance was not affected by the gap's placement at the upper and lower part of the ring. However, the gap's size of 0.2 $\mathrm{mm}$ placed at the left or right position of the ring has shifted up the resonant frequency from $8.1 \mathrm{GHz}$ to $11.8 \mathrm{GHz}$. For this study, it was shown that the mixture of full and incomplete ring elements has the potential to be utilized as an antenna to comprehend the operation of monopulse.
\end{abstract}

Keywords-Incomplete ring; full ring; dual frequencies; polarization-dependent

\section{INTRODUCTION}

The drawbacks in the parabolic reflector antenna have triggered the reflectarray antenna invention. A mixture of the guided elements mounted on a surface for reflecting radio waves in the favored path forms the reflectarray antenna. In the 1990s, the innovations making use of microstrip elements mounted on a grounded substrate material and arranged in an array became prominent [1].

Since reflectarray elements are printed on a flat surface, getting a phase plane is crucial. Numerous methods have been adapted to get the required phase plane. First of all, various patch element dimensions and a line phase delay were used, which fixed the phase delay in various paths out of the feed [2]. The second method is by utilizing the rectangular bipolar, or ring patch element of different sizes to guarantee the distinct scattering impedances from the elements. In this approach, different phases have to be offset by the delay of various feeds [1]. Finally, different polarization angles are utilized to respond to the variation in the feed's path length [3]. After all, the reflectarray antenna has its own weak point. The significant downside is its modest bandwidth characteristic, which relates to the elements design, focal length, and size of the aperture. In theory, the parabolic reflector has limitless bandwidth. For this reason, the broadband reflectarray is tough to oppose the parabolic reflector in terms of total performance [4].

A number of techniques have been executed to deal with the concern, such as utilizing microstrip patches in every size and shape, piled microstrip patch, and waveguide [3]. An easy, balanced shape such as square or ring patch element drawing in attraction could be enhanced for several frequency operations and give far better bandwidth [5]-[11]. Some studies state that a ring-shaped microstrip element is uncomplicated to take care of by changing its size. The wanted phase correction essential for reflectarray antenna aperture is acquired in this technique [12].

The source beam in monopulse radar is divided into several sections prior to sending the signals far from the antenna. The transmitted signals then strike an object at a distance and bounced back to the receiving antenna. After that, the received signals are distinguished among them to figure out the position of the object. Due to this, monopulse is often referred to as simultaneous lobe comparison. Monopulse technique has been utilized for overwhelming the lobe switching and conical scan sluggish searching speed, as well as incorrect angle indication discovered in radar tracking systems [13]. Several instances of monopulse applications are tracking radar, automotive radar as well as search and rescue radar. Cassegrain parabolic antennas are rather typical in monopulse radar systems. However, these systems' monopulse comparator is rather heavy, huge, and complicated to install. On the other side, microstrip patch antennas have several fascinating characteristics such as small, low profile, lightweight, and also quite economical to make. Due to the mentioned factors, a microstrip antenna is an excellent option for monopulse operation.

A number of approaches have been suggested to acquire monopulse's mode of operation. A millimeter-wave microstrip monopulse antenna was created by [14], while a bidirectionally-fed microstrip patch array was recommended by [15]. Nonetheless, the comparator network placed in the center of the antenna in the design ended up being a substantial obstruction for the aperture of the antenna. Various other studies include a double layers planar monopulse antenna [16], as well as a compact monopulse microstrip antenna array [17]. The author in [18] had the ability to create an electronically reconfigurable reflectarray antenna by using voltage-controlled liquid crystals as a substrate. However, at microwave frequencies, the readily available liquid crystals have a modest dielectric anisotropy. Subsequently, it limits the dynamic phase range offered [19]. 
This paper examines the incomplete and full ring element behaviour to validate its reliable use in the monopulse dualfrequencies system. It also features the gap's position and size within a ring concerning the reflection loss and reflection phase performance.

\section{METHODOLOGY}

A balanced-shape element such as a ring is frequently used in microstrip patch modern technology. The ring element's balanced geometry can be enhanced to obtain several operating frequencies and better bandwidth [20]. In the ring element's periodic arrays, the resonant frequency is established by the element's dimension, electrical properties of the material, and patch periodicity.

In this work, the patch element has been designed using CST Microwave Studio with specific boundary conditions to represent an infinite reflectarray. By adjusting the geometry of the elements, the scattering parameters of the modeled elements were analyzed later. Rogers RT/Duroid 5880 with $1.575 \mathrm{~mm}$ thickness, material permittivity $\varepsilon_{r}$ of 2.2 , and the loss tangent $(\tan \delta)$ of 0.0009 was selected as the substrate in the research. Since copper has a $100 \%$ electrical continuity rate, it was utilized for ground plane elements and ring patches. The patch and ground plane have $0.035 \mathrm{~mm}$ of thickness, while the element's periodicity of $10 \mathrm{~mm}$ x $10 \mathrm{~mm}$ is chosen. Fig. 1 shows the basics of an antenna design that has been developed. The element's dimension (in terms of internal radius $r_{i n}$ and external radius $r_{\text {out }}$ ), ring's width $w$, substrate periodicity ( $a$ and $b$ ), substrate thickness $t_{s}$, as well as substrate permittivity $\varepsilon_{r}$ established the resonant frequency of the antenna. Table I reveals the specification and its associated symbol made use of in the task.

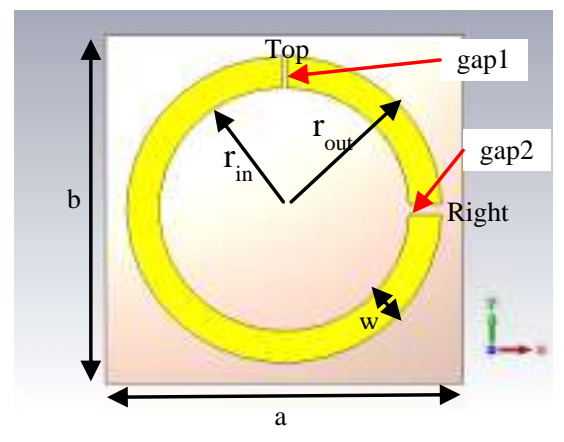

Fig. 1. Patch Antenna Design.

TABLE I. SPECIFICATION AND RELATED SYMBOL

\begin{tabular}{|l|l|}
\hline Parameter & Symbol \\
\hline Internal radius & $r_{\text {in }}$ \\
\hline External radius & $r_{\text {out }}$ \\
\hline Ring's width & $w$ \\
\hline Gap & gapl, gap2 \\
\hline Patch thickness & $t_{p}$ \\
\hline Periodicity & $a, b$ \\
\hline Substrate thickness & $t_{s}$ \\
\hline Substrate permittivity & $\varepsilon_{\mathrm{r}}$ \\
\hline Ground plane thickness & $t_{g}$ \\
\hline
\end{tabular}

A full or complete ring patch responses are independent relative to the incident polarization as a result of their balanced geometry. Nevertheless, the incomplete ring patches are polarization-dependent and produce different responses or reactions. The gap placement in an incomplete ring patch as displayed in Fig. 1 will form an unbalance geometry. In this study, the behavior of full ring, incomplete ring together with the position of the gap are analyzed.

\section{RESULTS AND DISCUSSION}

\section{A. Full Ring Element}

Fig. 2 displays a contrast of surface current distribution between round and ring patches. A round patch can be viewed to possess a nearly consistent surface current distribution. The current distribution for a ring is not uniform, on the other hand. Its current is concentrated at the right and left sections of the ring. In the meantime, the current distribution at the upper and lower part of the ring is practically minimal.

By incorporating an internal radius $r_{\text {in }}$ to round patch, the $S$ parameters have been outlined to investigate its impact on the resonant frequency. Fig. 3 presents the $\mathrm{S}$-parameter for various sizes of the ring. All ring patches in Fig. 3 are noted to make a distinct phase gradient. A thinner size ring (smaller $w$ ) will provide a sharp gradient that decreases its bandwidth performance. On the contrary, a thicker size ring (bigger $w$ ) will provide a more gradual gradient for the reflection phase curve. For example, the reflection phase gradient for $w=0.5$ $\mathrm{mm}$ is sharper than others, which reduces its bandwidth performance. So, the element with $w=0.5 \mathrm{~mm}\left(r_{i n}=3.5 \mathrm{~mm}\right)$ is not a good option in terms of bandwidth and return loss. These outcomes are in good agreement with previous researchers which says the reduction of reflected surfaces (patch) area will give a steep reflection phase curve [21] - [22]. In other words, a thicker ring performs better than a thin ring in terms of return loss and bandwidth, but a loss in a static phase range.

\section{B. Incomplete Ring Element}

Unbalanced or disproportional geometry is created with the existence of a gap in the ring element. As a result, the responses of an incomplete ring patch are actually polarizationdependent. When a gap is placed at a certain position, the patch's response is identical to the full ring. Having said that, at yet another position, its response is rather contrasted, in which the resonant frequency shifted up. This behaviour can be exploited to attain dual operating frequencies by using the same design of the antenna. It can be done by inserting an electronic switch within the gap in the right position. As a result, the patch's current flow or electrical continuity between the upper and lower part of the incomplete ring can be regulated by the switch. The patch's top position gap is required to compel the current to move via the switch when it is switched ON.

In general, the incomplete ring developed in the research is functioning within X-band. As a result, the value of $r_{i n}=3.5$ $\mathrm{mm}$ and $r_{\text {out }}=4.4 \mathrm{~mm}$ have been opted for. At this setup, the element gives an $8.10 \mathrm{GHz}$ resonant frequency. In Fig. 4, the incomplete ring geometry, which comprises four sections, i.e., Section A, Section B, Section C, and Section D, is shown. The 
angle of $0^{\circ}$ is at the bottom, while $90^{\circ}, 180^{\circ}$, and $270^{\circ}$ are at the right, top, and left, respectively. The corresponding resonant frequency for every $15^{\circ}$ gap rotation is represented in Table II. From the table, gaps at angles of $0^{\circ}, 90^{\circ}, 180^{\circ}$, and $270^{\circ}$ will give a single resonant frequency, $f_{1}$. The angle of $0^{\circ}$ and $180^{\circ}$ produces a resonant frequency of $8.1 \mathrm{GHz}$, while the angle of $90^{\circ}$ and $270^{\circ}$ produce a $12.5 \mathrm{GHz}$ frequency. Nevertheless, other angles of the gap will produce two resonant frequencies, $f_{1}$ and $f_{2}$. This design approach to produce multiple frequencies using a single ring with a gap is easier than the square ring combination and multiple rings introduced in [10] and [23], respectively. To simplify the design, only the gap angles that give a single resonant frequency, i.e., $0^{\circ}, 90^{\circ}, 180^{\circ}$, and $270^{\circ}$ were used for further analysis.

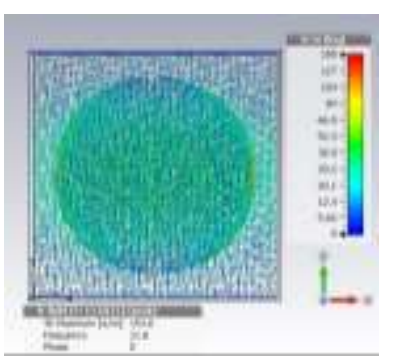

(a)

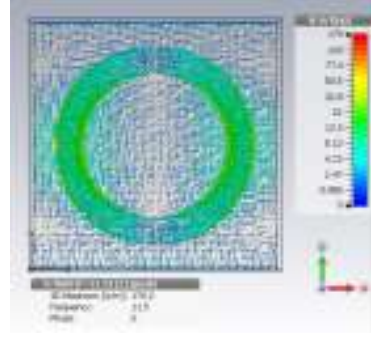

(b)
Fig. 2. Surface Current Distribution for (a) Round and (b) Ring Patch.

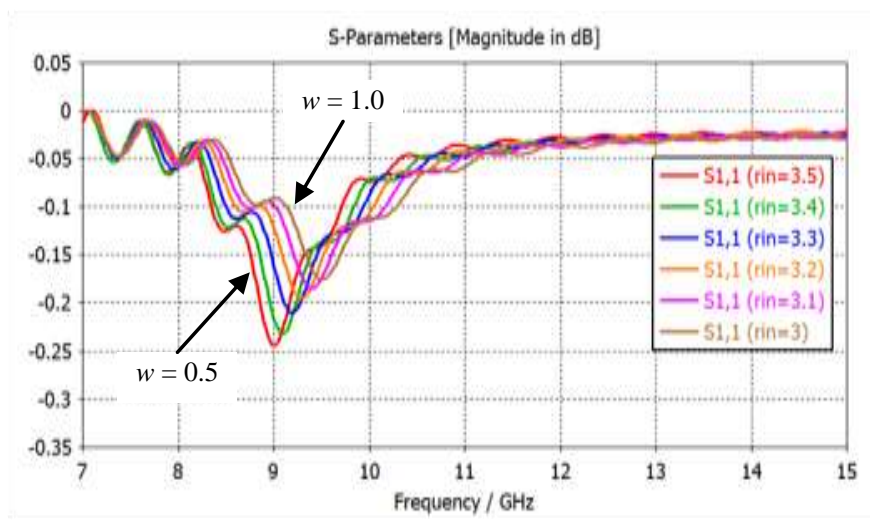

(a)

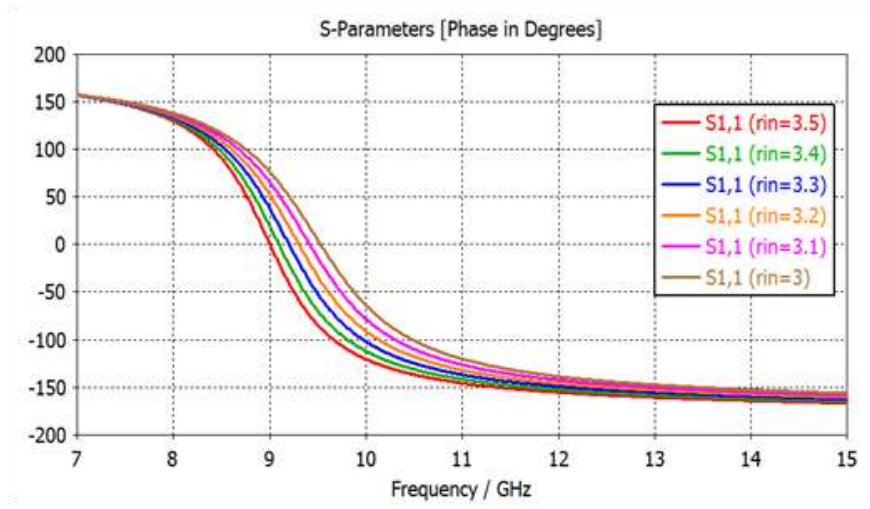

(b)

Fig. 3. S-Parameter in (a) Magnitude and (b) Phase for Ring Patch ( $r_{\text {out }}=4$ $\mathrm{mm})$ with different width, $w$.

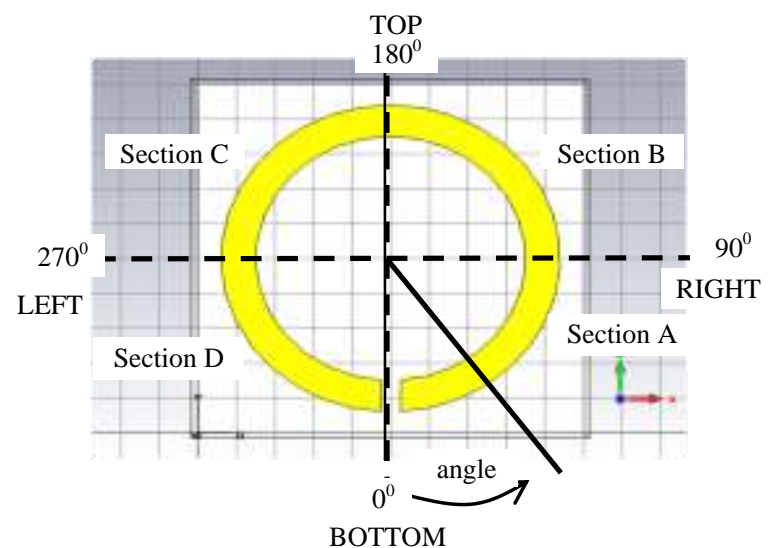

Fig. 4. Four Sections of an Incomplete Ring.

TABLE II. RESONANT FREQUENCY FOR AN ANGLE

\begin{tabular}{|l|l|l|l|l|l|}
\hline \multicolumn{2}{|l|}{ Angle $\left(^{\mathbf{9}}\right)$} & \multicolumn{2}{l|}{ Resonant frequency (GHz) } \\
\hline Sect. $\boldsymbol{A}$ & Sect. $\boldsymbol{B}$ & Sect. $\boldsymbol{C}$ & Sect. $\boldsymbol{D}$ & $\boldsymbol{f}_{\mathbf{1}}$ & $\boldsymbol{f}_{2}$ \\
\hline 0 & 180 & - & 360 & 8.1 & - \\
\hline 15 & 165 & 195 & 345 & 8.3 & 13.2 \\
\hline 30 & 150 & 210 & 330 & 8.6 & 13.1 \\
\hline 45 & 135 & 225 & 315 & 9.0 & 12.9 \\
\hline 60 & 120 & 240 & 300 & 9.5 & 12.8 \\
\hline 75 & 105 & 255 & 285 & 10.0 & 12.6 \\
\hline 90 & - & 270 & - & 12.5 & - \\
\hline
\end{tabular}

1) Gap insertion at the right position: Fig. 5 presents the incomplete ring element with a gap at the right position $\left(90^{\circ}\right.$ angles). At this position, the surface current density is at the highest level. Due to this, the presence of a gap will resist the current flow between the upper and lower part of the incomplete ring. The presence of a gap in the ring will cause its resonant frequency to move higher. For example, the gap's size of $0.4 \mathrm{~mm}$ moved the frequency from $8.10 \mathrm{GHz}$ to 12.20 GHz. The bigger the size of the gap, the higher the resonant frequency can be obtained. Fig. 6 highlights the surface current distribution, which is concentrated close to the gap, and minimal at the upper and lower part of the ring. Fig. 7 displays the $S_{11}$ parameter for an incomplete ring patch with a gap at the right position of the ring. It can easily be observed that resonant frequency went up rather significantly from the original frequency (full ring).

2) Gap insertion at the top: A gap at this position remains in parallel $\left(180^{\circ}\right.$ angle $)$ to the incident field, $E$. As presented in Fig. 8, the surface current distribution of the ring is rarely affected. The very minimal concentration of surface current can easily be observed at the bottom and on top sectors of the incomplete ring. Fig. 9 shows the S-parameters for the incomplete ring with a gap at the top placement. The reactions of this incomplete ring patch are practically comparable to the response of a full ring. For a gap of $0.2 \mathrm{~mm}$, the resonant frequency went up a little, from $8.10 \mathrm{GHz}$ to $8.12 \mathrm{GHz}$. The phase slope or gradient is identical for all incomplete rings with various dimensions of the gap. 


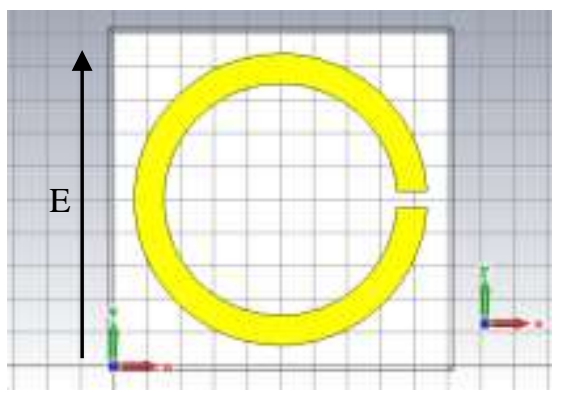

Fig. 5. Incomplete Ring with Right Position Gap.

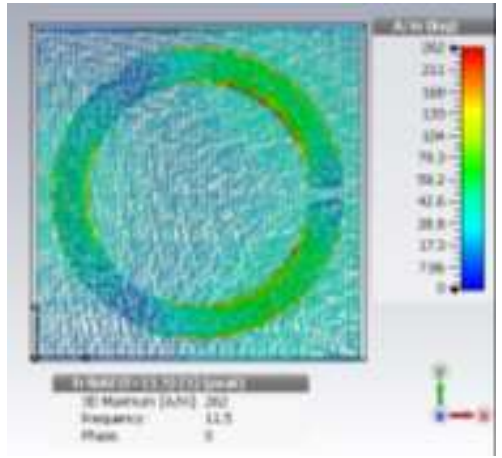

Fig. 6. Surface Current Distribution for an Incomplete Ring with a Gap at the Right Position.

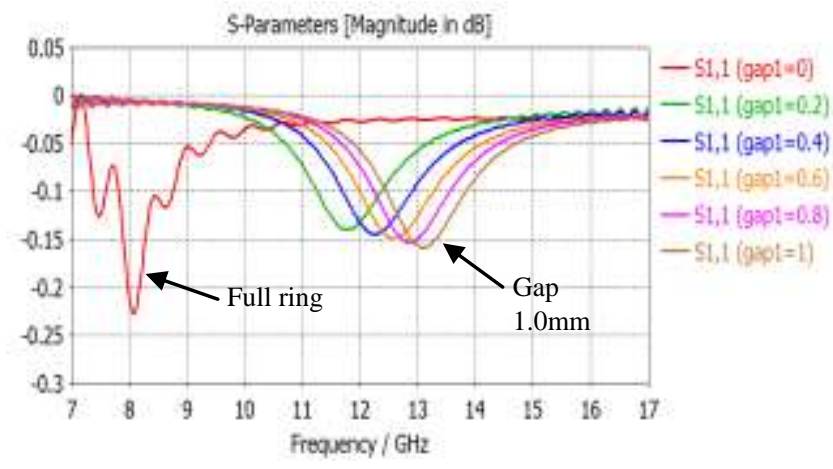

(a)

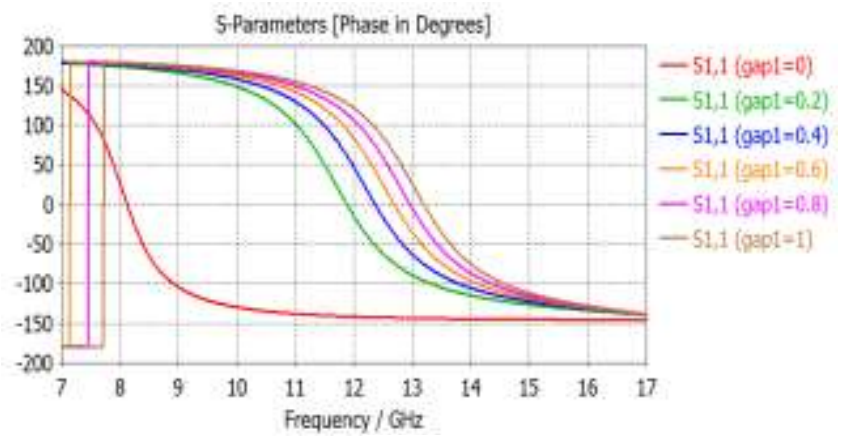

(b)

Fig. 7. S-Parameters for Incomplete Ring Patch with Right Position Gap.

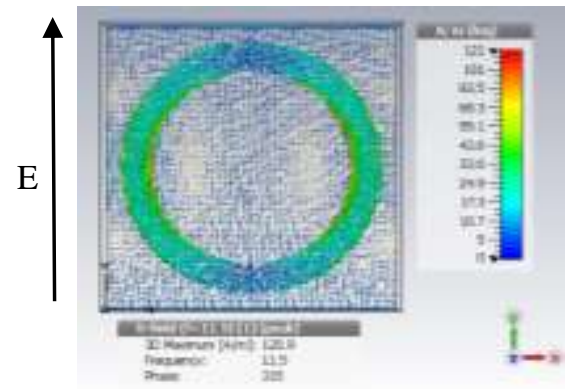

Fig. 8. Surface Current Distribution for an Incomplete Ring with Top Position Gap.

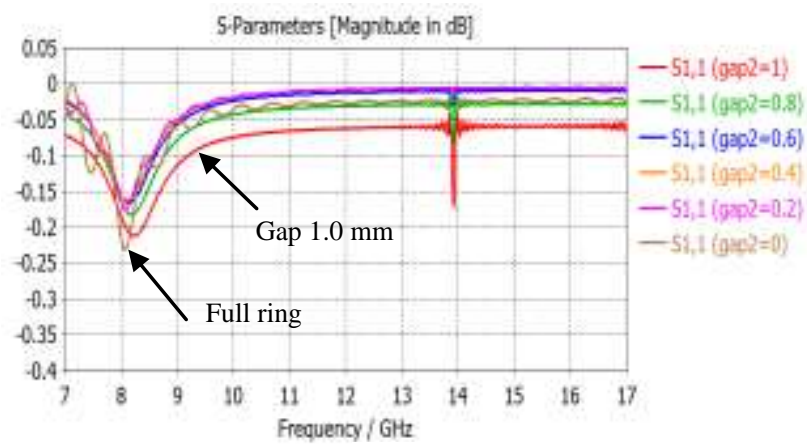

(a)

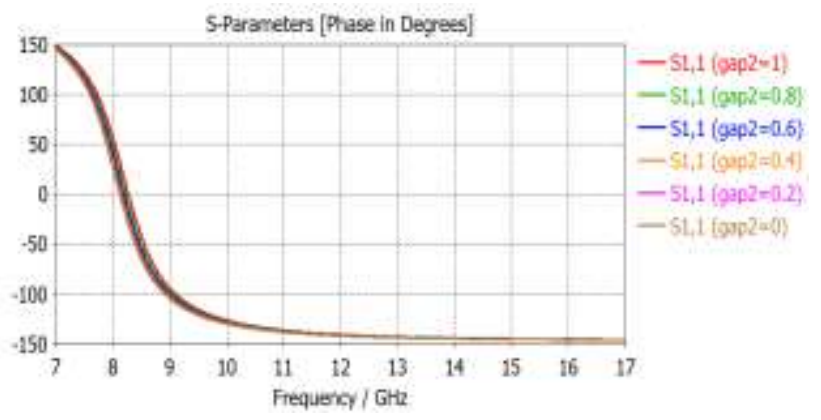

(b)

Fig. 9. S-Parameters for Incomplete Ring Patch with a Gap at the Top Position.

3) Gap insertion at the top and right: Table III summarizes the resonant frequency obtained for an incomplete ring with gaps at two positions. It was observed that the gap at the top or bottom (or even both) position almost did not affect the resonant frequency. However, the gap at the right or left (or both) position will move up the frequency. For example, the gap's size of $0.6 \mathrm{~mm}$ shifted the resonant frequency to 12.7 $\mathrm{GHz}$ and $15.9 \mathrm{GHz}$ for single and double gaps, respectively.

To attain dual frequencies, the very same incomplete ring patch element can be enhanced by putting an electronic switching component within a gap [11][24]. The switch aims to provide continuity or discontinuity between the bottom and top sections of the ring. This dual frequencies capability is an excellent attribute in acquiring monopulse mode of sum, $\sum$ and difference, $\Delta$. 
The location of an electronic switching within the patch is shown in Fig. 10. When the switch is ON, the upper and lower part of the ring is connected, leaving only a gap at the top position. In this condition, the incomplete ring behaves like a full ring. But if the switch is OFF, the ring will have two gaps at the top and right positions. This will cause the resonant frequency changes to a higher level.

The S-parameters for an incomplete ring with a switch at $\mathrm{ON}$ and OFF mode are shown in Fig. 11. During an ON mode, the resonant frequency of $8.10 \mathrm{GHz}$ was achieved. On the other hand, the frequency of $11.8 \mathrm{GHz}$ was obtained during an OFF mode.

TABLE III. RESONANT FREQUENCY FOR DUAL GAP OF INCOMPLETE RING

\begin{tabular}{|l|l|l|l|l|}
\hline \multirow{4}{*}{$\begin{array}{l}\text { Gap size } \\
(\mathbf{m m})\end{array}$} & \multicolumn{4}{|l|}{ Resonant frequency, $\boldsymbol{f}(\mathbf{G H z})$} \\
\cline { 2 - 5 } & $\begin{array}{l}\text { Bottom position } \\
\left(0^{\circ}\right)\end{array}$ & $\begin{array}{l}\text { Bottom \& Top } \\
\left(0^{\circ} \& 180^{\circ}\right)\end{array}$ & $\begin{array}{l}\text { Right } \\
\left(90^{\circ}\right)\end{array}$ & $\begin{array}{l}\text { Right \& Left } \\
\left(90^{\circ} \& 270^{\circ}\right)\end{array}$ \\
\hline 0.0 & 8.10 & 8.10 & 8.1 & 8.1 \\
\hline 0.2 & 8.12 & 8.12 & 11.8 & 14.3 \\
\hline 0.4 & 8.15 & 8.15 & 12.3 & 15.2 \\
\hline 0.6 & 8.20 & 8.20 & 12.7 & 15.9 \\
\hline 0.8 & 8.25 & 8.25 & 13.0 & 16.5 \\
\hline 1.0 & 8.30 & 8.30 & 13.2 & 17.0 \\
\hline
\end{tabular}

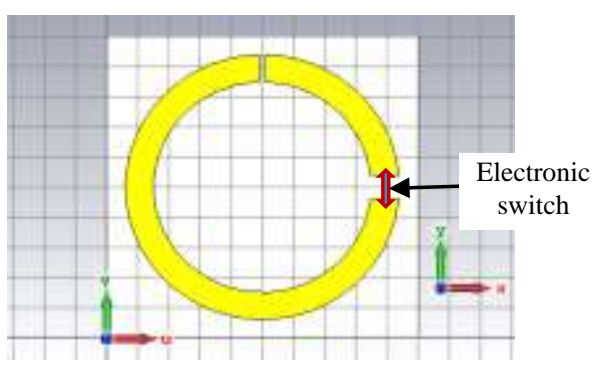

Fig. 10. An Electronic Switch within a Gap.

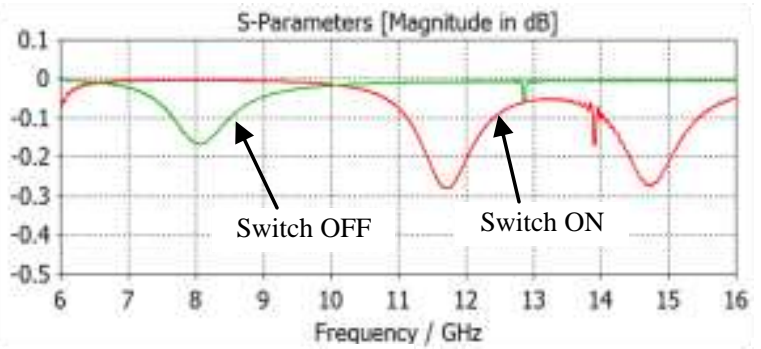

(a)

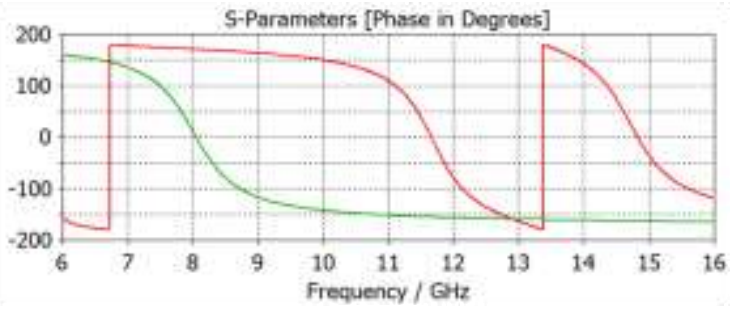

(b)

Fig. 11. S-Parameters in (a) Magnitude and (b) Phase for Incomplete Ring Patch with ON and OFF Mode.

\section{CONCLUSION}

The balanced geometry of the ring patch is able to be conveniently enhanced to acquire intended resonant frequencies. The research on the incomplete ring patch parameter with the incorporation of the gaps has actually been accomplished to confirm the use of them for dual frequencies operation. Observations from the studies reveal that the higher return loss and higher phase gradient or slope are triggered by the smaller width, $w$ of the ring element, which subsequently lowers its bandwidth performance. Additionally, the incomplete ring is shown to have polarization-dependent reactions. The position of a gap at particular placements of incomplete ring patch can be readjusted to get dual frequencies. As a result, the full and incomplete ring can be put together as an antenna's reflector to accomplish the operation of monopulse radar that requires such frequencies.

\section{ACKNOWLEDGMENT}

The authors would like to thank the Universiti Kebangsaan Malaysia under grant number GUP-2019-011 for financial support.

\section{REFERENCES}

[1] D. M. Pozar and T. A. Metzler, "Analysis of a reflectarray antenna using microstrip patches of variable size", Electronics Letters, vol. 29, no. 8, pp. 657-658, 1993.

[2] J. Huang, "Microstrip reflectarray", Antennas and Propagation Society International Symposium. AP-S. Digest. 2, pp. 612-615, 1991.

[3] J. Huang and R. J. Pogorzelski, "Microstrip reflectarray with elements having variable rotation angles", IEEE AP-S Symposium Digest, pp. 1280-1283, 1997.

[4] J. Huang and J. A. Encinar, Reflectarray Antennas, Press WileyInterscience, 2008.

[5] A. Smida, "Simulation and analysis of variable antenna designs for effective stroke detection," Int. Journal of Advanced Computer Science and Applications, vol. 11, no. 12, pp. 238-244, 2020.

[6] N. Ramli, S. K. Noor, T. Khalifa and N. H. A. Rahman, "Design and performance analysis of different dielectric substrate based microstrip patch antenna for $5 \mathrm{G}$ applications," Int. Journal of Advanced Computer Science and Applications, vol. 11, no. 8, pp. 77-83, 2020.

[7] A. Selamat, M. Ramli, N. Misran, M. F. Mansor and S. H. Zaidi, "A wide bandwidth element of solar reflectarray antenna with scanning ability", ARPN Journal of Engineering and Applied Sciences, vol. 13, no. 24, Dec. 2018.

[8] M. Ramli, A. Selamat, N. Misran, M. F. Mansor and M. T. Islam, "Design of capacitive integrated reflectarray radiating elements for beam scanning reconfigurability", Journal of Engineering and Applied Sciences, vol. 11, no. 1, pp. 106-111, 2016.

[9] M. Ramli, A. Selamat, N. Misran, M. F. Mansor and M. T. Islam, "Superposition of reflectarray elements for beam scanning with phase range enhancement and loss improvement", ARPN Journal of Engineering and Applied Sciences, vol. 11, no. 3, pp. 1755-1758, 2016.

[10] S. H. Yusop, N. Misran, M. F. Mansor, M. T. Islam and M. Abu, "A broadband reflectarray antenna concentric ring square element for dual frequency operation", Int. Journal of Applied Engineering Research, vol. 9, no. 24, pp. 26553-26562, 2014.

[11] M. Ramli, A. Selamat, N. Misran, M. F. Mansor and M. T. Islam, "Dual configurations reflectarray element in improving dynamic phase range and loss", Int. Journal of Applied Engineering Research, vol. 9, no. 24, pp. 23707-23716, 2014.

[12] N. Misran, R. Cahill, and V.F. Fusco, "Reflection phase response of microstrip stacked ring elements", Electronics Letters, vol. 38, no. 8, 2002.

[13] S. M. Sherman, Monopulse Principles and Technique, Dedham, MA: Artech House, 1984. 
[14] B. J. Andrews, T. S. Moore and A.Y. Niazi, "Millimeter-wave microstrip antenna for dual polar and monopulse applications," presented at the $3^{\text {rd }}$ Int. Conf. Antennas and Propagation, ICAP 83, Apr. $12-15,1983$.

[15] S. G. Kim and K. Chang, "Low-cost monopulse antenna using bidirectionally-fed microstrip patch array," Electronics Letters, vol. 39, no. 20, 2003.

[16] P. Rodriguez-Fernandez, A. Guillot-Duran, J. L. Masa-Campos and M. Sierra-Perez, "Planar monopulse antenna with radial line feeding," 2006 IEEE Antennas and Propagation Society International Symposium, pp. 3635-3638, July 2006.

[17] H. Wang, D. G. Fang, and X. G. Chen, "Compact single layer monopulse microstrip antenna array," IEEE Trans. Antennas Propagation, vol. 54, no.2, pp. 503-509, Feb. 2006.

[18] W. Hu, M. Y. Ismail, R. Cahill, H. S. Gamble, R. Dickie, V. F. Fusco, D. Linton, S. P. Rea and N. Grant, "Tunable reflectarray liquid crystal patch element”, IEE Electronics Letters, vol. 2, no. 9, pp. 509-511, 2006.

[19] M. Y. Ismail, W. Hu, R. Cahill, V. F. Fusco, H. S. Gamble, D. Linton, R. Dickie, S. P. Rea and N. Grant, "Phase agile reflectarray cells based on liquid crystals", Proc. IET IEE Microwaves Antennas and Propagation, August 2007.

[20] N. Misran, M. Y. Ismail and M. T. Islam, "Reflectarray antenna with radar cross-section reduction", Int. Journal of Integrated Engineering (Issue on Electrical and Electronic Engineering), vol. 2, no. 3, pp. 17-28, 2010.

[21] M. Y. Ismail, M. I. Abbasi and M. H. Dahri, "Phase characterization of reconfigurable reflectarray antennas", Int. Journal on Electrical Engineering and Informatics, vol. 5, no. 4, pp. 447-453, Dec. 2013.

[22] M. Y. Ismail, M. I. Abbasi, A. F. M. Zain, M. Amin and M. F. L. Abdullah, "Characterization of loss and bandwidth performance of reflectarray antenna based on lumped components", Int. Journal on Electrical Engineering and Informatics, vol. 2, no. 2, pp. 113-122, 2010.

[23] Y. Zhang, J. Liu, Z. Liang and Y. Long, "A wide-bandwidth monopolar patch antenna with dual-ring couplers", Int. Journal of Antennas and Propagation, vol. 2014, pp. 1-6, 2014.

[24] J. Perruisseau-Carrier and A. Skriverviky, "Monolithic MEMS-based reflectarray cell digitally reconfigurable over a 360 phase range", IEEE Antennas and Wireless Propagation Letters, vol. 7, pp. 138-141, 2008. 